\title{
O TRABALHO DO PROFESSOR DE EDUCAÇÃO FÍSICA NO CAPS: APROXIMAÇÕES INICIAIS
}

THE WORK OF PHYSICAL EDUCATION TEACHERS AT CAPS:

INITIAL APPROACHES

EL TRABAJO DE PROFESOR DE EDUCACIÓN FÍSICA EN CAPS: ENFOQUES INICIALES

Roberto Pereira Furtado*, Marcos Flávio Mércio de Oliveira**, Marcel Farias de Sousa*, Patrícia Santiago Vieira***, Ricardo Lira de Rezende Neves*, Gleyson Batista Rios ${ }^{\star *}$, William de Jesus Simon*

Palavras-chave

Educação Física. Assistência ao paciente. Serviços de saúde mental.

\section{Keywords}

Physical education. Patient care. Mental health services.

\section{Palabras clave}

Educación física. Atención AL paciente. Servicios de salud mental.
Resumo: Pesquisa realizada nos CAPS da cidade de Goiânia, com o objetivo de analisar as principais características da intervenção profissional da Educação Física. A pesquisa foi realizada a partir de observações participantes de professores de Educação Física que trabalham no CAPS e de relatos de experiência de três profissionais vinculados há pelo menos um ano a esta instituição, concedidos em forma de entrevista semiestruturada. Os resultados indicam que há aproximações do trabalho desenvolvido pelos professores de Educação Física com os princípios do CAPS e que apesar de avanços relevantes, os profissionais ainda estão aprendendo a lidar com os novos desafios.

Abstract: This article describes research conducted at Goiânia's CAPS to examine the core features of the professional intervention in Physical Education. The research was conducted through participant observation of Physical Education teachers working at CAPS as well as experience accounts by three professionals who have been working at that institution for at least a year. They were collected as semi-structured interviews. The results indicate that there are approximations of the work developed by Physical Education teachers with CAPS's principles and that despite relevant advances, professionals are still learning to deal with the new challenges.

Resumen: El deporte paralímpico es el principal medio de difusión de los deportes adaptados, también presentes en la escuela, siendo el término Educación Paralímpica el que engloba todas las actividades educativas relacionadas con este movimiento. Las principales formas de inserción encontradas fueron: el Día Paralímpico Escolar (DPE), en Europa, y las clases de Educación Física, en Brasil. Después de un levantamiento bibliográfico de artículos originales, fueron encontrados cambios en los aspectos generales relacionados con la inclusión de alumnos con discapacidad en clases de Educación Física. Este tema aún carece de estudios y propuestas adecuadas al contexto cultural para fomentar el deporte paralímpico en el ámbito académico y escolar.
* Universidade Federal de Goiás, Goiânia, GO. Brasil.

E-mail: cremerroberto@hotmail.com

** Secretaria Municipal da Saúde, Goiânia, GO. Brasil.

E-mail:marcosxis@yahoo.com.br

*** Instituto Federal de Goiás. Anápolis, GO, Brasil.

E-mail: ticinhasant@hotmail.com

Recebido em: 05-11-2013 Aprovado em: 10-09-2014

(c) (1) (8) Licence 


\section{INTRODUÇÃO}

A atual política brasileira de atenção em saúde mental tem suas bases no movimento denominado Reforma Psiquiátrica. Embora a Lei 10.216/01 (BRASIL, 2001), que apresenta os princípios de um novo modelo de cuidado em saúde mental, tenha sido promulgada no ano de 2001, este é um processo que ainda está em curso e que continua a demandar constantes reflexões. Os princípios constitutivos da Reforma Psiquiátrica indicam a construção de práticas de atenção às pessoas em sofrimento psíquico que superem a lógica desumanizadora da exclusão e reclusão existentes nos manicômios. Entretanto, para a construção de propostas alternativas ao paradigma manicomial os esforços devem ultrapassar a simples substituição do hospital psiquiátrico.

Com base nas experiências desenvolvidas em outros países, em especial na Itália, o Brasil está criando serviços substitutivos aos tradicionais hospitais psiquiátricos. Foi nesse contexto que surgiram os Centros de Atenção Psicossocial (CAPS), fundamentais para a articulação de uma rede de atenção em saúde mental, que oferecem um serviço de saúde aberto e comunitário pelo Sistema Único de Saúde (SUS).

O CAPS é um espaço de referência e tratamento para pessoas que sofrem de diversos transtornos mentais e demais quadros cuja severidade e/ou persistência justifica sua permanência em um dispositivo de cuidado intensivo. Seu objetivo é atender à população com acompanhamento clínico e promover a reinserção social dos usuários. Sua finalidade básica é ser um substituto às internações em hospitais psiquiátricos (BRASIL, 2004). Desse modo, 0 desenvolvimento de intervenções terapêuticas apresenta significativas distinções do que historicamente foi desenvolvido no modelo hospitalocêntrico. Assim, "[...] os CAPS podem oferecer diferentes atividades terapêuticas, que vão além das consultas e medicamentos, caracterizando o que hoje se denomina Clínica Ampliada" (BRASIL, 2004, p. 17).

A Reforma Psiquiátrica ampliou a presença de categorias profissionais no atendimento às pessoas em sofrimento psíquico. 0 Art. $4^{\circ}$ da Portaria n-336/GM de 2002 (BRASIL, 2002) indica que para compor a equipe técnica mínima das diferentes modalidades de CAPS alguns profissionais têm presença obrigatória e outros poderão ser inseridos, conforme a necessidade do serviço. É importante ressaltar que a presença da Educação Física não é obrigatória.

A intervenção nos CAPS deve ser realizada a partir de uma perspectiva interdisciplinar, na qual os profissionais dessas instituições estejam envolvidos e participem diretamente no atendimento ao usuário do serviço (BRASIL, 2004). Esse é um desafio necessário à consolidação dos CAPS.

Nessa perspectiva, apresentamos os resultados de uma pesquisa que realizou aproximações com a realidade do trabalho do professor de Educação Física nos CAPS de Goiânia, compreendendo algumas de suas características e rotinas de intervenção. Assim, acreditamos somar esforços para o fortalecimento do campo de conhecimento da Educação Física no que se refere à sua relação com a saúde mental, além de apresentar alguns subsídios que possam auxiliar na formulação e implementação de políticas públicas relacionadas com a Educação Física no SUS.

$\mathrm{O}$ artigo diz respeito à fase exploratória de uma pesquisa qualitativa que questiona, em um diagnóstico mais abrangente, as características do trabalho da Educação Física nos CAPS 
da cidade de Goiânia. Os vinte e um professores de Educação Física da Secretaria Municipal de Saúde de Goiânia que trabalham em CAPS foram convidados para concederem entrevistas em forma de relatos de experiência. Restringimos a amostra deste artigo aos três primeiros professores que se prontificaram a colaborar. As entrevistas foram concedidas ao grupo de pesquisadores entre agosto e novembro de 2012. Durante a entrevista, outras indagações consideradas pertinentes foram feitas aos professores, caracterizando-a como entrevista semiestruturada. Ainda para a coleta de dados, foram utilizadas informações de observações participantes de dois pesquisadores que também são profissionais de dois CAPS de Goiânia. Inicialmente, os dados foram ordenados, em seguida classificados para serem submetidos à análise final, como preconiza Minayo (1994). Na análise final, para o tratamento e análise dos dados, foi utilizada a análise de conteúdo, que visa: "[...] compreender criticamente o sentido das comunicações, seu conteúdo manifesto ou latente, as significações explícitas ou ocultas" (CHIZZOTTI, 2010, p. 98).

Para garantir o anonimato dos professores participantes, eles foram denominados Professor A, Professor B e Professor C. O Professor A é licenciado em Educação Física desde 2007, possui especialização em métodos e técnicas de ensino e trabalha no CAPS (Álcool e outras drogas infanto-juvenil) desde 2011. O Professor B é licenciado em Educação Física desde 2003, possui especialização em Educação Física Escolar e trabalhou no CAPS (Transtorno adulto) de 2005 a 2011. O Professor C é licenciado em Educação Física desde 2007, é Mestre em Sociologia e trabalha no CAPS (Álcool e outras drogas infanto-juvenil) desde 2011.

\section{A REFORMA PSIQUIÁTRICA EM PROCESSO}

Em geral, a concepção de que a pessoa com transtorno mental deve ser afastada do convívio social, devido à sua irracionalidade e à sua periculosidade, fundamenta e corrobora a existência de espaços como o manicômio. 0 manicômio deve ser compreendido não somente em sua dimensão física, mas como instituição difusora de valores e concepções acerca do que convencionalmente é definido como loucura (AMARANTE, 1992).

Apoiado numa lógica positivista, o manicômio se estrutura como um espaço em que a pessoa isolada, "livre" das interferências da sociedade, poderia se reestruturar, ao mesmo tempo em que a sociedade estaria protegida do perigo representado. Nessa perspectiva predomina a compreensão de que a instituição por si só poderia ser um tratamento para a pessoa com transtorno mental, que apenas receberia alta terapêutica a partir do momento em que 0 seu problema fosse "erradicado". Essa prática resulta em um grande número de pessoas abandonadas e submetidas a tratamentos desumanos.

No período anterior à Reforma Psiquiátrica brasileira, o paradigma hospitalocêntrico era a forma hegemônica de assistência psiquiátrica no país e foi amplamente questionado ao final dos anos 1970, destacando-se os efeitos das instituições asilares, das práticas de violência institucional e de segregação dos internos. Amarante (2007) apresenta diferentes autores que se debruçaram em reflexões e críticas a respeito da forma como os considerados loucos são tratados. Uma referência importante e com grande influência no processo de reforma psiquiátrica brasileiro foi Franco Basaglia, autor italiano que desenvolveu críticas radicais ao manicômio e à institucionalização de forma geral. Protagonizou experiências em comunidades terapêuticas, reconhecendo seus limites em análises posteriores de autocrítica (BASAGILA et al., 2005). 
Em outra perspectiva teórica, mas também com severas críticas ao processo de institucionalização proporcionado pelos manicômios, se encontram as análises de Goffman (2001). Ele explica que um dos importantes elementos que caracterizam o que ele denomina como instituições totais, presentes na sociedade moderna ocidental, é o seu fechamento em si, que impõe uma barreira e ruptura nas relações sociais dos sujeitos internos com o mundo externo. O autor compreende que há um processo de organização racional do espaço e das atitudes do interno em um plano racional geral que limita as suas relações com outras pessoas, restringido suas referências de autoridade àquelas presentes na instituição.

Para os três professores entrevistados, há nos CAPS um intenso debate e disputa de concepções a respeito do processo de Reforma Psiquiátrica. Assim, é possível afirmar que a Reforma Psiquiátrica está em processo e que ainda encontra fortes resistências e apresenta divergências entre os seus defensores, o que faz do CAPS um espaço de constante debate e reflexões. O Professor $\mathrm{C}$ identifica em sua instituição dois grupos, "os favoráveis e os não favoráveis à Reforma Psiquiátrica, assim as relações profissionais no trabalho coletivo e multiprofissional eram tensas". Porém, o mesmo professor explica que tais divergências não representavam grandes impactos nas relações pessoais entre os profissionais. De acordo com o Professor A, "os profissionais mais novos estão mais dispostos às mudanças rumo à reestruturação do trabalho hospitalar, repressivo e asilar, para um modelo psicossocial". Para que todas as divergências não inviabilizem o trabalho nos CAPS, o Professor B compreende que "o papel do coordenador é fundamental para convergir os discursos e ideias".

Como exemplo do processo permeado por disputas, encontra-se o princípio da desinstitucionalização e reinserção social do usuário, que ainda é foco de resistências. O Professor $B$ argumenta que, mesmo a realização de atividades fora do espaço do CAPS sendo fundamental para a desinstitucionalização e reinserção do usuário, este é um ponto ainda polêmico entre os profissionais. Segundo ele, "[...] ocorrem divergências quanto às propostas de saída dos usuários para outros locais de prática, é um ponto muito polêmico e que, na maioria das vezes, dificulta as relações profissionais".

Essa disputa e consequente debate envolvem também outros setores da sociedade, como os grupos políticos que assumem o Estado. Isso resulta em posicionamentos favoráveis ou contrários à reorientação da atenção. É importante que os gestores sejam vinculados ao serviço e que o compreendam em um contexto mais amplo. Essa é a posição dos três entrevistados. "Há uma luta política para que os diretores sejam pessoas vinculadas com a Unidade" (Professor B), porque há em vários CAPS diretores indicados politicamente que, geralmente, desconhecem o debate acerca da Reforma Psiquiátrica e as próprias especificidades do serviço ou mesmo defendem concepções contrárias à Reforma Psiquiátrica.

\section{A EDUCAÇÃO FÍSICA E O CAPS: PRODUÇÃO CIENTÍFICA E INTERVENÇÃO PROFISSIONAL}

A Educação Física pode apresentar grandes contribuições para os CAPS, desde que compreendida para além do enfoque estritamente biológico. Porém, ainda predominam pesquisas que privilegiam a dimensão biológica, desconsiderando outros determinantes no processo saúde-doença. Essa prática influencia o entendimento dos professores de Educação Física sobre a relação exercício físico e saúde. Conforme Bagrichevsky et al. (2003, p. 24), é hegemônica no campo a noção de "[...] 'atividade física (ou aptidão física) associada à saúde', 
[...] que busca advogar a existência de uma relação de 'causa e efeito', quase exclusiva, entre 'exercício' e 'saúde"'.

Essa é uma lógica que reduz "[...] o sujeito a objeto e prioriza aspectos quantitativos e individuais em detrimento da busca pelo significado das ações humanas" (FREITAS et al., 2006, p. 170). Não raro, as pessoas são culpabilizadas por seu estilo de vida pouco saudável, que culminaria no adoecimento, desconsiderando o modo como cada um está inserido na lógica da produção e suas condições de vida de uma forma geral.

Nesta perspectiva, os professores de Educação Física são também responsáveis por instaurar uma pedagogia do terror (FRAGA, 2006). 0 autor se refere à atuação pedagógica e dos discursos midiáticos pautados na culpa e no medo, a partir de números e estatísticas acerca dos malefícios do sedentarismo, que faz com que os sujeitos se sintam responsáveis por suas escolhas e pelas consequências de uma vida "desregrada".

Essa é uma prática presente não apenas no senso comum, mas também na própria produção considerada científica e na formação de professores de Educação Física. Dessa forma, muitos professores de Educação Física orientam seu trabalho por esse caminho, considerando o exercício físico como um remédio. Mira (2003) adverte que essa é uma linha de pensamento que deve ser problematizada, questionando a imposição das relações de causa e efeito e, inclusive, a sua validade científica.

Do ponto de vista dos princípios do SUS e da proposta dos CAPS, a lógica de trabalho deve se diferenciar da perspectiva tradicional, fundamentada no paradigma positivista de ciência. Portanto, o trabalho do professor de Educação Física deve pautar-se em outros referenciais que possibilitem ir ao encontro do que é proposto tanto pelas diretrizes do SUS quanto da atenção à saúde mental. Na tentativa de romper com essa perspectiva e criar outras possibilidades de ação, é importante que o campo da Educação Física englobe a compreensão de que as dimensões socioeconômicas e culturais também são determinantes da saúde, estabelecendo diálogos com a perspectiva da saúde coletiva.

São escassas as produções teóricas da Educação Física que abordam a saúde mental e os CAPS, principalmente aquelas produzidas a partir dos referenciais da saúde coletiva. Destacamos que Wachs (2008) apresenta experiências realizadas no Rio Grande do Sul e aponta a necessidade de que a Educação Física não seja imposta, mas que uma Educação Física emirja do próprio CAPS, possibilitando outras formas de organizar o cuidado na saúde mental. Outro destaque é a experiência relatada por Cirqueira (2009), que afirma que as atividades recreativas "despretensiosas" geram impactos positivos no cuidado e no processo de sociabilização. Contudo, o autor argumenta que atividades sistematizadas, que possuam intencionalidade pedagógica e que trabalhem os conteúdos da cultura corporal de movimento, são importantes até mesmo para legitimar a presença do professor de Educação Física nesse espaço.

A necessidade de ampliação do conceito de saúde e desconstrução da hegemonia do modelo biomédico nas ações da Educação Física é relatada pelos três professores como um desafio indispensável. Dessa forma, afirmam a "necessidade de ir além dos conteúdos tradicionais da Educação Física" (Professor A) para se trabalhar no CAPS e também a "necessidade de construir ações com base na cultura corporal. Superar a tradição dos saberes e práticas que são consagrados no campo da Educação Física, muitos deles não têm espaço ou significado na saúde pública" (Professor C). 
Entretanto, a concepção que as outras categorias profissionais apresentam a respeito da Educação Física tem se mostrado um entrave significativo. Os três entrevistados relatam que essa concepção reproduz a compreensão hegemônica do campo que, como explicado, é antagônica aos princípios da Reforma Psiquiátrica e dos CAPS. O professor C esclarece que "tal visão não surpreende, pois dentro do próprio campo da Educação Física existem profissionais e tendências pedagógicas com esta mesma visão. Além disso, esta é a visão hegemônica na sociedade".

Neste sentido, uma tarefa apresentada é a desconstrução da concepção que boa parte dos demais profissionais apresenta sobre as possibilidades de contribuição da Educação Física. Essa tarefa é desempenhada cotidianamente pelos entrevistados, na tentativa de explicitar que há uma contradição entre o discurso da Reforma Psiquiátrica e as ações que muitos dos profissionais que a defendem acreditam ser de responsabilidade da Educação Física.

\section{A EDUCAÇÃO FÍSICA NOS CAPS DE GOIÂNIA: UMA APROXIMAÇÃO}

A Rede de Atenção em Saúde Mental de Goiânia possui dez CAPS, sendo seis voltados para transtornos mentais e quatro para usuários de álcool e outras drogas. Todos os CAPS são de tipo II. Dois CAPS são Infanto-Juvenil, sendo que um é voltado a crianças e adolescentes usuários de álcool e outras drogas. A rede de Goiânia conta também com um Pronto Socorro Psiquiátrico, um Ambulatório de Psiquiatria e 277 leitos em clínicas conveniadas.

Em todos os CAPS de Goiânia há professores de Educação Física que são servidores públicos estatutários vinculados à Secretaria Municipal de Saúde, admitidos via concurso público. Os relatos dos entrevistados demonstram que a inserção inicial foi marcada pela inquietação a respeito da atuação específica da Educação Física no CAPS, pelo desconhecimento do campo da saúde mental e pelas descobertas a respeito das características do serviço público de saúde e das diretrizes do SUS. É compreensível a aflição inicial, por ser uma proposta recente e pouco abordada na formação inicial.

O Professor B não tinha nenhuma familiaridade com a saúde pública e ao chegar no CAPS "não sabia nem o que era transtorno mental". No mesmo sentido, o Professor A desconhecia o campo da saúde mental e ficou "assustado" com a política de redução de danos", porque sua formação familiar e religiosa contrariava muitos dos princípios defendidos por essa política. Muitos profissionais apresentam dificuldades no primeiro contato com os princípios da política de redução de danos, porque o paradigma hegemônico a respeito do álcool e outras drogas é pautado pela busca da abstinência.

Destacamos que o trabalho no campo da saúde mental também apresenta desafios do ponto de vista individual para o profissional. Os relatos indicaram que lidar com o sofrimento psíquico dos usuários é um limitador, principalmente no início de suas experiências, quando se deparam com uma realidade com a qual não estão acostumados e que não foi apresentada durante a formação. Nesta perspectiva, é possível afirmar que a inserção do profissional no serviço é permeada também por valores individuais, familiares, sociais, entre outros elementos constitutivos da identidade individual.

1 A Redução de Danos pode ser definida como uma política de saúde que se propõe a reduzir os prejuízos de natureza biológica, social e econômica do uso de drogas, pautada no respeito ao indivíduo e no seu direito de consumir drogas. As estratégias dessa política têm como objetivo reduzir o risco do dano associado a certos comportamentos, mas sem necessariamente interrompê-los. No caso da atenção integral aos usuários de drogas, implica na não exigência da abstinência, embora não a exclua. Tal visão muitas vezes é mal compreendida e polêmica, muitas vezes sendo confundida com a apologia ao consumo de drogas (NIEL; SILVEIRA, 2008). 
Avaliamos que a condição do CAPS que propicia um intenso debate teórico sobre 0 próprio trabalho é extremamente positiva e formativa para os profissionais. Nesta perspectiva, observa-se que a angústia inicial quanto ao que fazer nesse campo de trabalho, comum entre os três professores, cedeu lugar para um processo formativo. Todos os relatos indicam insegurança inicial, mas é perceptível o desenvolvimento das compreensões dos professores a respeito desse campo de trabalho.

Os professores entrevistados afirmam que há um cuidado especial por parte da equipe gestora do CAPS quando um novo profissional se apresenta para trabalhar na unidade. Tal cuidado tem o intuito de possibilitar uma aproximação com as especificidades e princípios que envolvem o trabalho com saúde mental no contexto da Reforma Psiquiátrica. Nos depoimentos foi explicado que, geralmente, os profissionais novatos nos CAPS de Goiânia antes de iniciarem efetivamente suas atividades são recebidos pelos demais profissionais e passam por uma fase de aproximação com a nova realidade de trabalho. Esse momento inicial é dedicado a estudos, observações e acompanhamentos de alguns grupos terapêuticos e outras atividades presentes na rotina do CAPS. Após o momento de aproximação com o serviço e suas rotinas, o novo profissional assume 0 atendimento ao usuário juntamente com a equipe do CAPS.

Os três professores concordam que o acolhimento do novo profissional depende bastante do envolvimento da coordenação do CAPS, por isso, cada unidade apresenta uma forma distinta e nem sempre ausente de conflitos. No caso do Professor B, o coordenador técnico da unidade foi o responsável por receber os novos profissionais. Explica ainda que o processo de aproximação inicial teve a duração de três meses. Já o Professor $A$ informou que o seu período de observação teve a duração de dois meses e, aos poucos, ele foi sendo integrado às oficinas e grupos terapêuticos. Por outro lado, o professor $\mathrm{C}$ relata que não passou por essa aproximação, por ter tido experiência em outro serviço de saúde mental.

\subsection{As primeiras atividades desenvolvidas}

O Professor $\mathrm{B}$, inicialmente, organizou um grupo de caminhada, corrida e ginástica que não teve desenvolvimento por falta de materiais e estrutura para o trabalho. Além disso, outra dificuldade que enfrentou foi a baixa adesão dos usuários ao projeto. Em seguida, desenvolveu um grupo com a prática de futebol entre os usuários, que exigia deslocamento de aproximadamente $2 \mathrm{~km}$ até o local da prática. Com o tempo, participou de parcerias com outras unidades de saúde com o intuito de realizar eventos interinstitucionais, que também ocorriam fora da unidade. Também construiu um projeto de tênis de campo com um dos usuários, sendo necessária a utilização de um espaço físico em local distante do CAPS. Outra atividade desenvolvida pelo Professor $\mathrm{B}$, que já tinha conhecimento no campo da música, foi a participação no grupo de convivência musical, que possibilitou maior criação de vínculo com os usuários.

Após a entrada no campo, o Professor A, primeiramente, participou do grupo de escuta terapêutica ativa. Ele considera que sua participação nesse grupo foi importante por permitir a criação de vínculo com os usuários. Logo depois, desenvolveu um projeto de lutas de solo visando trabalhar a autoestima e o contato corporal. Contudo, por falta de estrutura, esse trabalho não teve continuidade. Relata ainda que também trabalhou com jogos com bola, desenvolveu oficinas de áudio e vídeo com a temática "livre arbítrio e as consequências de suas ações" e atividades aquáticas de recreação. Ele utilizou, por algum tempo, as experiências que 
desenvolvia na escola como professor de Educação Física na educação básica e se dedicou muito à leitura e aos cursos de formação.

Fica evidente nos relatos a mobilização dos conhecimentos advindos de experiências anteriores não diretamente relacionados com a Educação Física. O Professor B sintetiza da seguinte forma: "as habilidades pessoais do profissional são as balizadoras do processo: ensina-se aquilo que se pratica".

A necessidade apresentada pelos professores de mobilizar conhecimentos diversos pode ser compreendida a partir da própria característica da instituição e de seus princípios. Neste sentido, apresenta relevância significativa o acesso aos conhecimentos que vão além do saber sistematizado de um campo ou área de conhecimento. Tal aspecto nos remete aos debates sobre a formação em saúde e põe em questão as possíveis contribuições de uma formação ampla para o profissional da saúde.

\subsection{A rotina de trabalho nos CAPS}

De modo geral, pode-se afirmar que o professor de Educação Física participa, assim como os demais profissionais, das seguintes atividades: acolhimento, momentos de planejamento e reuniões (estudo de caso, reunião técnica e geral, entre outras), oficinas e grupos terapêuticos, atendimento de familiares, equipe de referência e miniequipe, busca ativa, visita domiciliar e matriciamento.

O primeiro momento do usuário no CAPS é o acolhimento. Como esse serviço é de porta aberta, ou seja, recebe o usuário a qualquer momento sem um agendamento prévio, 0 acolhimento é uma prática realizada sempre que necessário. 0 professor $C$ explica que "a relação com os usuários pauta-se pela construção cotidiana do vínculo terapêutico". No trabalho em saúde, a construção do vínculo entre o profissional e o usuário é fundamental para que a relação seja de confiança e, sobretudo, mais humanizada.

O acolhimento é realizado por uma equipe multiprofissional que através da escuta qualificada buscará identificar as necessidades dos usuários e de seus familiares que procuram o serviço. $O$ momento do acolhimento é fundamental tanto para o estabelecimento de vínculos quanto para o planejamento do atendimento ao usuário, pois é quando as necessidades são identificadas. O Professor B afirma que "a partir de uma escuta qualificada dos usuários decide-se, em reuniões coletivas, os conteúdos que serão trabalhados". É de acordo com as necessidades dos usuários que os grupos terapêuticos e oficinas em que ele participará são definidos. $O$ Professor $B$ destaca que o ponto de partida para o planejamento das atividades a serem realizadas são as condições estruturais e materiais do CAPS e dos recursos do território. Os professores afirmaram buscar parcerias com outras instituições do território para a utilização de espaços físicos como piscinas, quadras de tênis e academias de ginástica. Esta é uma importante ação, pois, por um lado, tenta minimizar problemas estruturais da instituição e, por outro, contribui com o processo de desinstitucionalização e reinserção social do usuário.

De acordo com os entrevistados, o vínculo entre o profissional e o usuário é difícil de ser estabelecido principalmente nas primeiras aproximações com o campo devido à nova realidade e aos preconceitos que trazem a respeito da pessoa com transtorno mental. A esse 
respeito, o Professor B chama a atenção para a necessidade de que "as relações com os usuários devem ser direcionadas a não ter 'medo' dos mesmos".

Embora haja alguns riscos, principalmente para o usuário que demanda alguns cuidados especiais, a sensação de "ter medo" dos usuários e das atividades a serem realizadas em toda a rotina do trabalho aos poucos é superada, de acordo com o relato dos entrevistados. O professor B explica que, em episódios onde o usuário precisa ser contido por apresentar comportamentos agressivos, é necessário "conter sem machucar, o que exige uma formação específica que não é comum no ensino das profissões nos cursos de formação". Acrescenta ainda o mesmo professor que são fundamentais nesse processo "as reuniões técnicas voltadas para as condutas éticas e de tratamento, a partir de estudos de caso".

Em geral, o profissional que realizou o acolhimento do usuário torna-se o seu terapeuta de referência (TR), sendo responsável por conduzir o projeto terapêutico e orientá-lo dentro do serviço. Além disso, deve estabelecer contato com a família, avaliar as metas traçadas e dialogar com a equipe técnica do CAPS a respeito do caso (Brasil, 2004). Todos os três professores entrevistados tiveram várias experiências como TR de alguns usuários e relatam que essa é uma dimensão importante da rotina de trabalho nos CAPS.

As oficinas e os grupos terapêuticos são atividades semelhantes. De acordo com o Professor $\mathrm{C}$, há uma avaliação dos profissionais da área da saúde mental de que as atividades em grupo são muito importantes no atendimento ao usuário. Tal importância está relacionada, dentre outros elementos, com o princípio de reinserção social que acompanha a lógica de organização dos CAPS. Um dos exemplos de oficinas foi relatado pelo Professor C: "atualmente desenvolvo trabalho junto aos usuários utilizando as técnicas e jogos do Teatro do Oprimido, em conjunto com uma colega arteterapeuta. A formação no Teatro do Oprimido ocorreu em curso de capacitação promovido pela própria Secretaria Municipal de Saúde".

O apoio matricial e a busca ativa são duas outras importantes atividades presentes na rotina do CAPS, com os três professores relatando já as terem realizado. De acordo com Chiaverini (2011, p. 13), o "matriciamento ou apoio matricial é um novo modo de produzir saúde em que duas ou mais equipes, num processo de construção compartilhada, criam uma proposta de intervenção pedagógico-terapêutica". Na lógica do matriciamento, os casos dos usuários com transtornos mentais ou dependência de drogas devem ser atendidos e, em grande parte, resolvidos na própria atenção primária, cabendo aos profissionais do CAPS dar suporte a esta equipe. Propõe-se uma articulação da equipe de referência, vinculada à Unidade Básica de Saúde e à equipe do CAPS que deve "proporcionar a retaguarda especializada da assistência, assim como um suporte técnico-pedagógico, um vínculo interpessoal e 0 apoio institucional no processo de construção coletiva de projetos terapêuticos junto à população" (CHIAVERINI, 2011, p. 14-15). Deste modo, são corresponsáveis pelos usuários da saúde mental.

A busca ativa tem a intenção "de ir à contracorrente do automatismo da demanda espontânea, no sentido de cartografar as necessidades de saúde para além dos agravos de notificação compulsória de determinado território" (LEMKE; SILVA, 2010, p. 285). Segundo Lemke e Silva (2010), a busca ativa é uma postura ativa do trabalhador do SUS, que possibilita acessar o mundo do usuário do serviço, o seu território, as suas necessidades propiciando o estabelecimento de vínculo terapêutico e a integração do trabalhador do SUS ao meio cultural do usuário. Estes autores sintetizam que a busca ativa demarca, sobretudo, um posicionamento político. 
Entretanto, os professores afirmaram que a busca ativa é realizada quando um usuário está muito ausente, e raramente é realizada em outra situação. Uma equipe de profissionais do CAPS se dirige até o domicílio do usuário e procura compreender os motivos e orienta o seu retorno ao CAPS.

O professor C é ainda o responsável por coordenar o grupo de familiares em seu CAPS. Ele explica que o "grupo de familiares caracteriza-se por ser um grupo operativo, visando auxiliar aos familiares a lidarem com o sofrimento do usuário". Um dos principais desafios para o CAPS é a grande rotatividade dos usuários, que nem sempre frequentam o serviço com a necessária continuidade. $O$ professor $B$ afirma que este "é o ponto central para 0 trabalho desenvolvido no CAPS. Esta dificuldade provoca a descontinuidade das atividades". Por isso a importância do trabalho de acompanhamento familiar e busca ativa.

\subsection{Contradições e desafios para a intervenção}

A construção de propostas metodológicas para o trabalho no CAPS é um desafio a ser superado, de acordo com a fala dos entrevistados. $O$ professor $C$ analisa a necessidade de "superar a distância entre os profissionais das diversas unidades de saúde pública, visando aproximação e construção coletiva de um corpo de conhecimentos no campo da saúde mental". Já o professor B apresenta a importância de construção de metodologias avaliativas que proporcionem maior compreensão dos resultados do trabalho: "avaliar a 'evolução' do tratamento ainda é uma dificuldade a ser enfrentada" (Professor B). Cabe ressaltar que, devido aos próprios princípios do CAPS, o esforço de avaliar os resultados do trabalho não pode ser restrito a cada campo de conhecimento, mas deve ser um esforço interdisciplinar.

A intervenção dos professores é resultado tanto de seus interesses e perspectivas políticas como das condições de trabalho dos CAPS. De acordo com o Professor B, "para montar um grupo multiprofissional a saída era partir para a afinidade entre os profissionais ou definir pela coincidência do horário de trabalho". A situação relatada evidencia como as condições objetivas podem contradizer as perspectivas dos profissionais ou as políticas do SUS. Assim, as necessidades dos usuários e os princípios dos CAPS podem ficar subsumidos à realidade das instituições. Mas alguns relatos também demonstram esforços da equipe em superar limitações existentes em busca de um atendimento mais adequado ao preconizado pelas políticas para o serviço.

Nesse sentido, é necessário compreender que os CAPS e a própria Reforma Psiquiátrica como um todo não estão livres das contradições de nossa sociedade e são instituições e processos permeados por disputas que envolvem interesses individuais e políticos de classe.

Neste sentido, podemos analisar o trabalho multiprofissional, a partir do que apresenta o professor C: "o fato de haver uma equipe multiprofissional e que atua de forma interdisciplinar faz com que a maioria dos usuários não diferencie um profissional de Educação Física de um enfermeiro, por exemplo". A única ressalva feita pelo mesmo professor diz respeito ao que ele avalia ainda como certa hegemonia do campo da Psicologia e da Psiquiatria: "a não ser no caso da Psicologia e da Psiquiatria, que realizam atendimentos específicos, para a maioria dos usuários do serviço todos os membros da equipe técnica são considerados terapeutas". Explica ainda que "em geral, existe um peso grande da área da Psicologia no CAPS, o que em algumas situações coloca esta área reproduzindo práticas de hegemonia tais quais a prática 
médica". Essa característica, aliada a outros aspectos do cotidiano da instituição, evidencia que o CAPS também é um espaço de contradições e que muitos limites ainda não foram superados e talvez não seja possível no âmbito institucional. Entretanto, é importante ressaltar que o mesmo professor reconhece que o CAPS avança bastante no trabalho multiprofissional e afirma que "ainda assim, a relação entre os profissionais no CAPS se pauta pela construção coletiva e pelo debate a partir de enfoques diferenciados, segundo as contribuições de cada área de atuação".

\section{CONSIDERAÇÕES FINAIS}

Analisar a Educação Física no contexto da saúde mental e da atenção psicossocial requer a identificação de potenciais contribuições de produções teóricas do campo da Educação Física e da maneira pela qual a Educação Física está inserida nesses serviços. O CAPS é uma instituição estratégica na atenção psicossocial onde se materializam disputas relacionadas ao processo de Reforma Psiquiátrica. Entre os próprios defensores da Reforma Psiquiátrica, há muitos debates sendo realizados a respeito dos caminhos a serem trilhados. Essas disputas e debates estão presentes no cotidiano dos CAPS e contribuem para a formação dos profissionais que lá trabalham. É necessário compreender que os limites ainda presentes são constitutivos de qualquer processo de transformação em curso. Os profissionais ainda estão aprendendo a lidar com os novos desafios.

No mesmo sentido, podemos compreender a situação da Educação Física que se depara com um novo campo, uma nova forma de lidar com o usuário do serviço e outro tipo de prática relacionada ao processo saúde e doença. Tudo isso põe no debate da Educação Física brasileira a necessidade de avaliar suas contribuições para a saúde a partir de uma concepção que não seja restrita ao paradigma biomédico.

\section{REFERÊNCIAS}

AMARANTE, Paulo Duarte de Carvalho. A trajetória do pensamento crítico em saúde mental no Brasil: planejamento na desconstrução do aparato manicomial. In: KALIL, Maria Eunice Xavier. (Org.). Saúde mental e cidadania no contexto dos sistemas locais de saúde. São Paulo: Hucitec, 1992. P. 103119.

AMARANTE, Paulo Duarte de Carvalho. Saúde Mental e Atenção Psicossocial. Rio de Janeiro: FIOCRUZ, 2007.

BAGRICHEVSKY, Marcos; OLIVEIRA, Alexandre Palma de; ESTEVÃO, Adriana (Org.). A saúde em debate na Educação Física. Blumenau: Edibes, 2003. v. 1.

BASAGLIA, Franco et al. Considerações sobre uma experiência comunitária. In: BASAGLIA, Franco.

Escritos selecionados em saúde mental e reforma psiquiátrica. Organização de Paulo Amarante. Rio de Janeiro: Garamond, 2005. p. 11-40.

BRASIL. Ministério da Saúde. Portaria no 336 estabelece CAPS I, CAPS II, CAPS III, CAPS i II e CAPS ad II. Brasília, DF: 19 fev. 2002. Disponível em: http://dtr2004.saude.gov.br/susdeaz/ legislacao/arquivo/39_Portaria_336_de_19_02_2002.pdf. Acesso em: 29 jun. 2013.

BRASIL. Ministério da Saúde. Secretaria de Atenção à Saúde. Departamento de Ações Programáticas Estratégicas. Saúde mental no SUS: os centros de atenção psicossocial. Brasília: Ministério da Saúde, 2004. 
BRASIL. Presidência da República. Casa Civil. Lei n. 10.216 de 6 de abril de 2001. Dispõe sobre a proteção e os direitos das pessoas portadoras de transtornos mentais e redireciona o modelo assistencial em saúde mental. Diário Oficial da União, Brasília, DF: 9 abr. 2001, p. 2.

CHIAVERINI, Dulce Helena (Org.). Guia prático de matriciamento em saúde mental. [Brasília, DF]: Ministério da Saúde. Centro de Estudo e Pesquisa em Saúde Coletiva, 2011.

CHIZZOTTI, Antonio. Pesquisa em ciências humanas e sociais. 11. ed. São Paulo: Cortez, 2010.

CIRQUEIRA, Márcio Vinicius B. Reflexões acerca da cultura corporal no espaço de atenção à Saúde Mental. In: RABELO, Ionara Vieira; TAVARES, Rosane C; FARIA, Yuse R. A. de (Org.). Olharesexperiências de CAPS: Centro de Atenção Psicossocial. Goiânia: Kelps, 2009. p. 53-66.

FRAGA, Alex Branco. Exercício da informação: governo dos corpos no mercado da vida ativa. Campinas: Autores Associados, 2006.

FREITAS, Fabiana Fernandes de; BRASIL, Fernanda Kundrát; SILVA, Cinthia Lopes da. Práticas Corporais e saúde: novos olhares. Revista Brasileira de Ciências do Esporte, Campinas, v. 27, n. 3 , p. 169-183, maio 2006.

GIL, Antonio Carlos. Métodos e técnicas de pesquisa social. São Paulo: Atlas, 2008.

GOFFMAN, Erving. Manicômios, prisões e conventos. Tradução Dante Moreira Leite. 7. ed. São Paulo: Perspectiva, 2001. (Coleção Debates).

LEMKE, Ruben Arthur; SILVA, Rosane Azevedo Neves da. A busca ativa como princípio político das práticas de cuidado no território. Revista Estudos e Pesquisas em Psicologia, Rio de Janeiro, v. 10, n. 1, p. 281-295, 2010.

MINAYO, Maria Cecília de. Souza. Ciência, Técnica e Arte: o Desafio da Pesquisa Social. In: MINAYO, Maria Cecília de. Souza. (Org.). Pesquisa social: teoria, método e criatividade. Petrópolis: Vozes, 1994. p. 9-15.

MIRA, Carlos Magallanes. Exercício físico e saúde: da crítica prudente. In: BAGRICHEVSKY, Marcos; OLIVEIRA, Alexandre Palma de; ESTEVÃO, Adriana (Org.). A saúde em debate na Educação

Física. Blumenau: Edibes, 2003. v. 1, p.169-191.

NIEL, Marcelo; SILVEIRA, Dartiu Xavier da. Drogas e redução de danos: uma cartilha para profissionais de saúde. Programa de Orientação e Atendimento a Dependentes (PROAD). Universidade Federal de São Paulo (UNIFESP). Ministério da Saúde. São Paulo, 2008. Disponível em: < https://www.google.com.br/?gws_ C+Marcelo\%3B+SILVEIRA\%2C+Dartiu+Xavier+da.+Drogas+e+redu\%C3\%A7\%C3\%A30+de+danos >. Acesso em: 19 mar. 2014.

WACKS, F. Educação física e saúde mental: uma prática de cuidado emergente em Centros de Atenção Psicossocial (CAPS). Dissertação (Mestrado) - Escola de Educação Física, Universidade Federal do Rio Grande do Sul, Porto Alegre, 2008. 